MAJOR ARTICLE

\title{
Pathogen-Specific Risk Factors and Protective Factors for Acute Diarrheal Illness in Children Aged 12-59 Months in São Paulo, Brazil
}

\author{
J. Sobel, ${ }^{1}$ T. A. T. Gomes, ${ }^{2}$ R. T. S. Ramos, ${ }^{2}$ M. Hoekstra, ${ }^{1}$ D. Rodrigue, ${ }^{1, a}$ V. Rassi, ${ }^{2}$ and P. M. Griffin ${ }^{1}$ \\ ${ }^{1}$ Centers for Disease Control and Prevention, Atlanta, Georgia; and ${ }^{2}$ Escola Paulista de Medicina, São Paulo, Brazil
}

(See the editorial commentary by Lima and Guerrant on pages 1552-4)

Diarrheal diseases are a leading cause of childhood morbidity and mortality in Latin America. Most studies have focused on infants but not on older children. We enrolled 505 children (age, 12-59 months) with diarrhea and age-matched controls in a case-control study in São Paulo, Brazil. Independent risk factors for diarrhea included another household member with diarrhea (matched odds ratio [mOR], 8.1; attributable fraction [AF], $0.17 ; P<.001)$ and consumption of homemade juice (mOR, 1.8; AF, $0.10 ; P=.01)$; protective factors included boiling of the baby bottle or nipple (mOR, $0.60 ; \mathrm{AF}, 0.19 ; P=.026$ ), childcare at home (mOR, 0.58 ; AF, 0.12 ; $P=.004$ ), and piped sewage (mOR, 0.58; AF, 0.05; $P=.047$ ). Hand washing by the caretaker after helping the child defecate protected against Shigella infection (mOR, $0.35 ; P<.05)$. Preparation of rice, beans, or soup in the morning and serving it to children after noon were associated with enterotoxigenic Escherichia coli infection (mOR, 8.0; $P<.05)$. In these poor households, $28 \%$ of cases of diarrhea in 1-4-year-old children was attributable to easily modifiable exposures.

More than 3 million children die each year of diarrheal diseases in developing counties [1], and many times this number have the long-term complications of malnutrition, growth retardation, and immune impairment [2-5]. In Latin America, diarrheal illness is responsible for $\sim 10 \%$ of childhood deaths [6]. Epidemiologic studies can identify risk factors and lead to recommendations of simple, immediate, and effective risk-reduction measures to decrease morbidity and mortality [7-12].

Risk factors vary with the child's age, the pathogens

Received 17 November 2003; accepted 22 January 2004; electronically published 11 May 2004.

Presented in part: 39th Annual Meeting of the Infectious Diseases Society of America, San Francisco, California, 25-28 0ctober 2001 (abstract 850).

a Present affiliation: Lexington Infectious Diseases Consultants, Lexington, Kentucky.

Reprints or correspondence: Dr. Jeremy Sobel, Foodborne and Diarrheal Diseases Branch, Centers for Disease Control and Prevention, MS-A38, 1600 Clifton Rd. NE, Atlanta, GA 30333 (jsobel@cdc.gov).

Clinical Infectious Diseases 2004; 38:1545-51

(C) 2004 by the Infectious Diseases Society of America. All rights reserved. $1058-4838 / 2004 / 3811-0006 \$ 15.00$ involved, and the local environment [13]. Most studies have not analyzed risk factors according to different age groups or specific pathogens, except for the study by Blake et al. [7], who described pathogen- and age-specific risk and protective factors in 500 urban infants in São Paulo, Brazil. Our study complements the work by Blake and colleagues [7] in exploring pathogen- and agespecific risk and protective factors for diarrheal illness in children aged 1-5 years from the same urban area.

\section{PATIENTS AND METHODS}

Case patients and control subjects were recruited from the hospital emergency department of Hospital Infantil de Menino Jesus, a large teaching hospital that provides free medical care to persons of mostly lower socioeconomic status in São Paulo, a metropolis of $>14,000,000$ inhabitants. Patients and control subjects were recruited from March 1989 through March 1990. Case patients were children aged 12-59 months who presented to the emergency department with a chief complaint of acute 
diarrhea (i.e., diarrhea of $\leqslant 7$ days of duration, with an interval of $\geqslant 14$ days from the last episode of diarrhea), Monday through Thursday, 9:00 A.M. to 2:30 P.M. Subjects were enrolled sequentially as they presented. The sample was weighted to include approximately equal numbers of case patients from each of the following age groups: 12-23 months, 24-35 months, and 36-59 months. A control subject was identified for each case patient by selecting the next child registered in the emergency department who had not had gastrointestinal signs or symptoms during the preceding 30 days, who was not admitted with the diagnosis of fever of unknown origin, and who was in the same age group as the case patient. Children who had been treated with antimicrobial agents were not excluded.

Informed consent was obtained from the parents of subjects, and human experimentation guidelines of the US Department of Health and Human Services and those of the Escola Paulista de Medicina of Sao Paulo were followed in the conduct of this clinical research.

Two pediatricians interviewed the accompanying adult using a standardized 169-item questionnaire. The questionnaire sought personal, clinical, and epidemiologic information. Questions about exposures pertained to the period before the onset of diarrhea (or acute illness, for control subjects). Medical risk factors queried included previous hospitalization and antimicrobial treatment in the 14 days before illness. Child-care exposures included day care situation, breast feeding, use and handling of baby bottles and their contents, and consumption of assorted foods and beverages consumed and their manner of preparation and storage. Household conditions investigated included number of people and rooms in the household, presence of household members with diarrhea before the onset of the child's illness and whether such persons prepared food, and presence of other children in the household-specifically, other children in diapers. Hygiene-focused risk factors included availability of running water and taps, water storage and handling practices, type of toilet and availability of hand washing facilities, caretaker's hand washing practices, and animals within and outside the house. Also sought was information on level of education and income.

The interviewers obtained 2 rectal swab specimens from each child at the time of the interview (one for bacterial culture and the other for viral testing). Laboratory methods have been described elsewhere [4]. Stools were examined for rotavirus; adenovirus; Salmonella, Shigella, Campylobacter, and Aeromonas species [14, 15]; and 4 categories of diarrheogenic Escherichia coli: enteroinvasive, enteropathogenic, enterohemorrhagic, and enterotoxigenic (ETEC), identified by DNA probe [16]. Enteropathogenic E. coli strains were defined as those positive for the EAF plasmid and for the eaeA gene [17].

Case-control pairs were excluded from the analysis of risk and protective factors if the case patient's stool specimen yielded $>1$ enteric pathogen or if the control subject's stool sample yielded any enteric pathogen. Aeromonas species were not considered to be pathogens because their pathogenicity in diarrheal illness is unproven. Descriptive analyses were performed using SAS software, version 6.12 (SAS Institute).

Age was defined as a 3-category variable (12-23 months, 2435 months, and 36-59 months). Univariate analyses with dichotomous and continuous exposure variables and the multilevel age category variable were performed using SAS software, version 6.12. ORs were calculated from the Cox proportional hazards model generated by the PHREG procedure in SAS software. Risk and protective factors significant at the $P \leqslant$ .05 level were examined for independent relationship with diarrheal illness in multivariate logistic regression analysis, controlling for interaction and confounding. In the final multivariate model, there was no confounding, age category was not an effect modifier, and exposure-exposure interactions were not present. Attributable risk was calculated for risk and protective factors significant at the $P \leqslant .05$ level in the multivariate model using the method of Bruzzi et al. [18], optimally interpreted under the assumption that the cases in the model can be considered a random sample of all cases in the population and that the disease is "rare" (i.e., it has an incidence of $\leqslant 10 \%$ ).

\section{RESULTS}

Selection of subjects and descriptive statistics. Five hundred five case-control pairs were enrolled. Thirty-one percent of case patients were aged 12-23 months, 32\% were aged 24-35 months, and 37\% were aged 36-59 months. Case patients and control subjects did not differ significantly from each other in sex distribution (269 case patients [53\%] were male, compared with 260 control subjects [51\%]), monthly income (median, US\$180 vs. US\$189), and highest school grade attained by head of household (third grade for both). Ninety-one case-control pairs were excluded from the analysis of risk and protective factors because the case patient was carrying multiple pathogens (37 pairs) and/or the control was carrying a pathogen (58 pairs). Four hundred fourteen pairs remained.

The enteric pathogens identified in the stools of the 414 cases used in the analysis of risk and protective factors and their associated symptoms are detailed in table 1 . Of 414 cases, 66 (16\%) were infected with Shigella species, 48 (12\%) were infected with rotavirus, and $25(6 \%)$ were infected with ETEC. The diagnoses of control subjects included respiratory infections and pharyngitis (59\%), dermatological conditions (15\%), allergic reactions (without further specification; 4\%), trauma (2\%), and other problems (20\%).

Univariate and multivariate analysis of all cases: risk factors and protective factors for diarrheal illness. Risk factors significantly associated with diarrheal illness on univariate analy- 
Table 1. Frequency of pathogens in $\mathbf{4 1 4}$ cases used in the analysis of risk and protective factors, and frequency of symptoms for select pathogens.

\begin{tabular}{lcccccc}
\hline & \multicolumn{5}{c}{ No. (\%) of cases } \\
\cline { 2 - 7 } Pathogen & All cases & Vomiting & Bloody stools & Fever & Catarrh & $\begin{array}{c}\text { Pain or crying } \\
\text { while defecating }\end{array}$ \\
\hline Shigella species & $66(16)$ & $30(46)$ & $35(53)$ & $51(77)$ & $35(53)$ & $37(57)$ \\
S. flexneri & 37 & $\ldots$ & $\ldots$ & $\ldots$ & $\ldots$ & $\ldots$ \\
S. sonnei & 25 & $\ldots$ & $\ldots$ & $\ldots$ & $\ldots$ & $\ldots$ \\
S. dysenteriae & 3 & $\ldots$ & $\ldots$ & $\ldots$ & $\ldots$ & $\ldots$ \\
S. bodyii & 1 & $\ldots$ & $\ldots$ & $\ldots$ & $\ldots$ & $\ldots$ \\
Rotavirus & $48(12)$ & $39(81)$ & $2(4)$ & $26(54)$ & $33(69)$ & $16(33)$ \\
Adenovirus & $0(0)$ & $\ldots$ & $\ldots$ & $\ldots$ & $\ldots$ & $\ldots$ \\
ETEC & $25(6)$ & $12(48)$ & $2(8)$ & $9(38)$ & $12(48)$ & $11(46)$ \\
EIEC & $16(4)$ & $\ldots$ & $\ldots$ & $\ldots$ & $\ldots$ & $\ldots$ \\
EPEC & $9(2)$ & $\ldots$ & $\ldots$ & $\ldots$ & $\ldots$ & $\ldots$ \\
Campylobacter species & $7(2)$ & $\ldots$ & $\ldots$ & $\ldots$ & $\ldots$ & $\ldots$ \\
Salmonella species & $4(1)$ & $\ldots$ & $\ldots$ & $\ldots$ & $\ldots$ & $\ldots$ \\
STEC & $1(1)$ & $\ldots$ & $\ldots$ & $\ldots$ & $\ldots$ & $\ldots$ \\
Total & $176(42)$ & $\ldots$ & $\ldots$ & $\ldots$ & $\ldots$ & $\ldots$ \\
\hline
\end{tabular}

NOTE. EIEC, enteroinvasive Escherichia coli; EPEC, enteropathogenic E. coli; ETEC, enterotoxigenic E. coli; STEC, Shiga toxin-producing E. coli.

sis were the following: having a household member ill with diarrhea during the 2 weeks before the patient's illness, having a household member with diarrhea serving food in the 2 weeks before the patient's illness, introduction of a new food to the patient's diet, being cared for at another home with children from other families during the 7 days before illness, feeding the child homemade fruit juice from a baby bottle during the 7 days before illness, sharing a toilet with another household, and having another child aged $<5$ years in the household (table 2). Protective factors for diarrheal illness were the following: boiling of the baby bottle, boiling of the bottle's nipple, having a toilet attached to a public sewage system, and child care in the child's own home before illness (table 2). A lower proportion of the caretakers of case patients who fed the child homemade fruit juice in a baby bottle reported boiling the bottle or bottle nipple, but this association did not reach statistical significance. There was no significant difference between case patients and control subjects with regard to previous hospitalization or antimicrobial treatment, breast-feeding, type of nonhuman milk and other specific food items fed to the child, number of persons or rooms in the household, availability of municipal water, water storage practices, caretaker's hand washing practices, exposure to animals, or the head of household's level of education or salary.

A multivariate model was created using the factors that were significant in univariate analysis. The variable "care for the child at home" was included and the variable "care for that child at another home" was excluded, because they were highly correlated and because the former affected a greater proportion of patients. Similarly, the variable "presence of another household member with diarrhea" was included and the variable related to food preparation by this person was excluded, because they were highly correlated. A single variable was created for the variables of boiling the baby's bottle or the nipple of the bottle. The variable "exposure to new food" was excluded because of concerns about recall bias.

In the final multivariate model, there was no confounding, age category was not an effect modifier, and exposure-exposure interactions were not present. The multivariate model demonstrated independent association between diarrheal illness and the following exposures: diarrhea in another household member during the 2 weeks preceding the case's illness, and feeding the case child homemade juice in a baby bottle during the week before illness were risk factors for disease. Care for the child at home for $\geqslant 4$ of the 7 days preceding illness, boiling baby bottles or bottle nipples, and having a toilet attached to piped sewage were protective (table 3). Attributable risk was calculated for these variables and is presented in table 3. For the protective factors, the exposure rates were inverted to express the result in terms of attributable fraction.

Pathogen-specific analyses. On univariate analysis, ETEC infection was significantly associated with preparing rice, beans, or soup in the morning and serving these foods to the child in the evening (table 4). This risk was independent of ownership of a refrigerator (data not shown). The risk of Shigella infection was significantly associated with consumption of powdered milk, and protection was significantly associated with washing of the caretaker's own hands after helping young children defecate. 
Table 2. Risk factors and protective factors significantly associated with diarrheal illness in matched pairs of children aged 12-59 months in São Paulo, Brazil, March 1989 through March 1990.

\begin{tabular}{|c|c|c|c|c|}
\hline Exposure & $\begin{array}{l}\text { No. (\%) of } \\
\text { case patients }\end{array}$ & $\begin{array}{l}\text { No. }(\%) \text { of } \\
\text { control subjects }\end{array}$ & $\begin{array}{l}\text { Matched OR } \\
\quad(95 \% \mathrm{Cl})\end{array}$ & $P$ \\
\hline \multicolumn{5}{|l|}{ Risk factor } \\
\hline $\begin{array}{l}\text { Other household member with diarrhea } \\
\text { in } 2 \text { weeks before illness onset }\end{array}$ & $78(15)$ & $13(3)$ & $7.50(3.88-14.51)$ & .0001 \\
\hline $\begin{array}{l}\text { Household member with diarrhea serving food } \\
\text { in } 2 \text { weeks before illness onset }\end{array}$ & $18(4)$ & $5(1)$ & $4.25(1.43-12.63)$ & .009 \\
\hline Introduction of new food to child's diet & $60(15)$ & $16(4)$ & $4.14(2.31-7.43)$ & .0001 \\
\hline $\begin{array}{l}\text { Child at informal day care } \geqslant 4 \text { of } 7 \text { days before } \\
\text { illness onset }\end{array}$ & $38(9)$ & $23(6)$ & $1.83(1.03-3.26)$ & .04 \\
\hline $\begin{array}{l}\text { Consumption of homemade juice from baby bottle } \\
\text { in } 7 \text { days before illness onset }\end{array}$ & $96(23)$ & $74(18)$ & $1.56(1.01-2.40)$ & .04 \\
\hline Share toilet with other household & $124(30)$ & $95(23)$ & $1.48(1.07-2.04)$ & .02 \\
\hline Other child $<5$ years old in household & $186(45)$ & $158(38)$ & $1.32(1.03-1.61)$ & .006 \\
\hline \multicolumn{5}{|l|}{ Protective factor } \\
\hline $\begin{array}{l}\text { Child cared for at home } \geqslant 4 \text { of } 7 \text { days before } \\
\text { illness onset }\end{array}$ & $297(72)$ & $329(80)$ & $0.64(0.46-0.89)$ & .0009 \\
\hline Toilet attached to piped sewage & $359(87)$ & $377(92)$ & $0.60(0.38-0.96)$ & .03 \\
\hline Baby bottle nipple cleaned by boiling & $157(38)$ & $184(64)$ & $0.52(0.33-0.80)$ & .003 \\
\hline Baby bottle cleaned by boiling & $149(72)$ & $180(44)$ & $0.47(0.30-0.73)$ & .0009 \\
\hline
\end{tabular}

\section{DISCUSSION}

This study is unique in combining an extensive evaluation of risk and protective factors with comprehensive microbiology in an at-risk age group that is often underrepresented in studies of diarrheal illness. Of the many potential exposures examined, 2 independent risk factors and 3 independent protective factors for diarrhea in children were identified. Three of these factors can be addressed by behavior modifications, and 2 are related to socioeconomic status and so are best modified by societal changes. In addition, we found that $12 \%$ of children without diarrhea harbored enteric pathogens, and $7 \%$ of children with diarrhea harbored $>1$ enteric pathogen.

Presence of a household member with diarrhea preceding the case's illness was the risk factor with the highest OR and a high attributable fraction for disease, a finding reported by Blake et al. [7] for children aged $<12$ months as well. This suggests a high risk of intrahousehold transmission and the need for specific measures to reduce transmission. Presence of an infected household member was strongly associated with rotavirus infection but not with Shigella infection. Because rotavirus typically affects younger children, this may indicate that ill household contacts were young children, but because we did not ask about the age of the ill contacts, we cannot confirm this. Ill members of the same household as case patients did not generally participate in food preparation; further emphasis on hand washing and limitation of physical contact between ill and healthy young children to prevent transmission is indicated [19].
To our knowledge, exposure to homemade juice in a baby bottle has not been previously described as a risk factor for diarrhea with this degree of specificity. Some property of juices may explain the risk, such as support of bacterial growth or a tendency to form a residue that is difficult to wash and serves as nidus of contamination. It is of interest that use of a baby bottle alone was not a risk factor, nor was exposure to other items in a baby bottle (i.e., cow's milk, powdered milk, or boiled or unboiled water). Caretakers might consider milk to be a higher-risk food and discard unconsumed portions promptly, while assuming that juice is safer and therefore leaving it longer in the bottle. Evaluation of caretaker practices, as well as a study of pathogen growth tendencies in juices, could evaluate this hypothesis. The proportion of illnesses attributable to not boiling the bottle or nipple was $19 \%$. The practice may protect against diarrhea because it cleans bottles more effectively or prevents contamination with unclean water, rags, and hands.

The protective effect of having a toilet attached to a piped sewage system is consistent with extensive research documenting the strong relationship between proper disposal of feces and prevention of diarrheal illness $[9,20,21]$. This effect has been shown in some studies to be strongest in urban areas $[9,22]$, probably as part of a complex interaction between the direct effect of sewerage in reducing environmental fecal contamination and a tendency to defecate closer to the home in crowded urban slums and other factors [23]. The model showed no interaction between piped sewage and age category, yet a substantial proportion of the case patients in the study were not old enough 
Table 3. Predictors of diarrheal illness in children aged 12-59 months, São Paulo, Brazil, on multivariate analysis.

\begin{tabular}{lccc}
\hline Variable & OR $^{\mathrm{a}}(95 \% \mathrm{Cl})$ & $\begin{array}{c}\text { Attributable } \\
\text { fraction }\end{array}$ & $P^{\mathrm{b}}$ \\
\hline $\begin{array}{l}\text { Household member with diarrhea in 2 weeks } \\
\text { before case patient's illness }\end{array}$ & $8.09(4.13-15.85)$ & 0.17 & .0001 \\
$\begin{array}{l}\text { Baby consumed homemade juice from bottle } \\
\text { in 7 days before case patient's illness }\end{array}$ & $1.76(1.14-2.71)$ & 0.10 & .010 \\
$\begin{array}{l}\text { Baby bottle or bottle nipple cleaned by boiling } \\
\begin{array}{l}\text { Child cared for at home } \geqslant 4 \text { of } 7 \text { days before } \\
\text { case patient's illness }\end{array}\end{array}$ & $0.69(0.49-0.96)$ & $0.19^{\mathrm{c}}$ & .026 \\
\begin{tabular}{l} 
Toilet attached to piped sewage \\
\hline
\end{tabular} & $0.58(0.40-0.84)$ & $0.12^{\mathrm{c}}$ & .0037 \\
\hline
\end{tabular}

${ }^{\text {a }}$ Risk ratio generated by PHREG procedure in SAS software, version 6.12 (SAS Institute), is interpreted here as the OR.

${ }^{b} P$ value for the Wald $\chi^{2}$ test that the parameter estimate for variable is different from 0 , adjusting for other variables in model.

${ }^{c}$ For protective factors, the exposure definitions were inverted to express the result in terms of attributable fraction.

to use a toilet, suggesting that the exposure is a marker for a less contaminated environment. Simple targeted interventions, such as hand washing after defecation and before food preparation, can interrupt the fecal-oral transmission route [19, 21].

The association of diarrheal illness with day care is well known, although the data are not always consistent. This study indicates that care of the child at home during the week preceding illness was protective and that informal day care in private homes was a significant risk factor for diarrheal illness. Studies from North America [24] and Scandinavia [25] have shown that household day care is safer than formal day care, whereas in West Africa, the situation resembles that shown in this study [11]. Similarly, Blake et al. [7] previously found that attending a formal day care center, but not an informal one, in
São Paulo was a risk factor for diarrhea in infants under 1 year of age. It is likely that the association of day care with illness is due to deficiency in hygiene. If the proportion of children in day care facilities increases, this exposure could account for an even larger proportion of illnesses in this population.

It is noteworthy that multivariate analysis showed no interaction between exposures and the age categories of case patients, despite there being differences in diet, mobility, immunity, and other factors between children in the second year of life and the fifth year of life. We did not explore the incidence of diarrhea in the different age groups, but others have reported a marked decrease in the incidence of specific pathogens from age 12-23 months to 24-36 months [26]. Although the incidence of diarrhea may decrease through childhood, our data

Table 4. Matched ORs for risk factors and protective factors associated with infection with specific pathogens in stools from children aged 12-59 months in São Paulo, Brazil, March 1989 through March 1990.

\begin{tabular}{|c|c|c|c|c|}
\hline Risk and protective factors & $\begin{array}{l}\text { All subjects } \\
(n=176)\end{array}$ & $\begin{array}{c}\text { Shigella } \\
\text { species } \\
(n=66)\end{array}$ & $\begin{array}{l}\text { Rotavirus } \\
(n=48)\end{array}$ & $\begin{array}{c}\text { ETEC } \\
(n=25)\end{array}$ \\
\hline Other household member with diarrhea in 2 weeks before case patient's illness & $7.50^{\mathrm{a}}$ & 0.99 & 7.0 & 4.0 \\
\hline Other child $<5$ years old in household & $1.32^{\mathrm{b}}$ & 1.0 & 1.0 & 1.51 \\
\hline Household member with diarrhea serving food in 2 weeks before case patient's illness & $4.25^{\mathrm{b}}$ & 2.0 & 2.4 & 2.0 \\
\hline Toilet shared with other household & $1.48^{\mathrm{C}}$ & 0.72 & 1.40 & 0.83 \\
\hline Child at informal day care $\geqslant 4$ of 7 days before case patient's illness & $1.83^{\mathrm{C}}$ & 0.43 & 0.80 & \\
\hline Consumption of powdered milk & 1.18 & $2.22^{\mathrm{C}}$ & 0.50 & 0.33 \\
\hline Hand washing of caretaker's own hands after helping young children defecate & 0.74 & $0.35^{\mathrm{c}}$ & 1.25 & 1.0 \\
\hline Preparation of rice in the morning and serving to child after noon & 0.90 & 1.73 & 1.0 & $8.0^{\mathrm{C}}$ \\
\hline Preparation of beans in the morning and serving to child after noon & 1.0 & 1.0 & 1.0 & $8.0^{\mathrm{C}}$ \\
\hline Preparation of soup in the morning and serving to child after noon & 2.0 & 1.0 & 1.0 & $9.0^{\mathrm{C}}$ \\
\hline
\end{tabular}

NOTE. ETEC, enterotoxigenic E. coli.

a $P<.001$.

b $P<.01$

${ }^{c} P<.05$. 
indicate that risk factors for diarrhea and the appropriate control measures do not change for children in the second through fifth year.

The association of ETEC infection with preparation of rice, beans, or soup in the morning and consumption by the child in the afternoon was independent of refrigerator ownership and likely reflects a custom of food storage on a stove. A high prevalence of ETEC in the environment or on food preparers' hands and preferential survival of ETEC in these foods are possible reasons for the association with this pathogen. Caretakers need to be educated about the importance of proper food storage and thorough heating before consumption.

This study has several limitations. Potential for recall bias exists, because all risk factors and protective factors were determined from response to a questionnaire; no direct observation was undertaken. Most questions, however, were obvious and related to ongoing behaviors. Control subjects consisted of children presenting to the emergency department with nondiarrheal conditions, and, as such, may not have been representative of the underlying population without diarrhea. However, because accumulated evidence suggests that broad categories of risk for diarrhea and the illnesses prevalent among the controls (respiratory infections and dermatologic conditions) are similar [27], results are more likely to be biased toward the null. This study did not demonstrate an association between income level, education, or crowding in the house and diarrheal illness, in contrast to the study by Blake et al. [7], which involved infants from the same population, and studies from other settings. It is unlikely that the population studied had a uniform standard of living. The guardians of $79 \%$ of case patients but of only $46 \%$ of control subjects reported their income. Selection bias caused by nonreporting of income by higher-earning control families could obscure an inverse relationship between income level and diarrheal disease. The attributable fraction we calculated is an estimate of the proportion of cases due to each exposure (or absence of a protective factor) in the analytic model used. It is not an estimate of the change in disease incidence that might result from eliminating particular risk factors, because counterfactual modeling would be required to estimate changes resulting from modifying the exposure dynamic.

In conclusion, because this study explored a broad range of risk factors for diarrheal illness and pathogen-specific infection, we suggest specific, practical interventions to decrease childhood diarrheal morbidity in children aged 1-4 years in poor families in São Paulo and similar areas. Boiling of baby bottles and bottle nipples, careful attention to hygienic preparation of fruit juices, targeted hand washing, and proper storage and adequate heating of specific foods may reduce disease. In addition, interventions to reduce transmission from individuals in the household and the day care facility should be studied.

\section{References}

1. Murray C, Lopez A. Summary: global burden of diseases. Cambridge: Harvard University Press, 1996.

2. Adair L, Guilky D. Age-specific determinants of stunting in Filipino children. J Nutr 1997; 127:314-20.

3. Dowd P, Heatley R. The influence of undernutrition on immunity. Clin Sci 1984; 66:241-8.

4. Bittencourt SA, Leal Mdo C, Rivera J. Diarrhea and growth among children under 18 months of age in Rio de Janeiro. Bull Pan Am Health Organ 1993; 27:135-44.

5. Posey DL, Linkins RW, Couto Olivera MJ, Monteiro D, Patriarca PA. The effect of diarrhea on oral poliovirus vaccine failures in Brazil. J Infect Dis 1997; 175(Suppl 1):S258-63.

6. Organizacion Panamericana de la Salud/Organizacion Mundial de la Salud. Boletin AIEP. Vol 2. 1997:7.

7. Blake PA, Ramos S, MacDonald L, Rassi V, et al. Pathogen-specific risk factors and protective factors for acute diarrheal disease in urban Brazilian infants. J Infect Dis 1993; 167:627-32.

8. Quick RE, Venczel LV, Gonzalez O, et al. Narrow-mouthed water storage vessels and in situ chlorination in a Bolivian community: a simple method to improve drinking water quality. Am J Trop Med Hyg 1996; 54:511-6.

9. VanDerslice J, Popkin B, Briscoe J. Drinking water quality, sanitation, and breast-feeding: their interactive effects on infant health. Bull WHO 1994; 72:589-601.

10. Jelliffe DB, Jelliffe EFP. Feeding utensils and infant diarrhea in less developed countries [comment]. Am J Dis Child 1982; 136:667.

11. Molbak K, Jensen H, Ingholt L, Aaby P. Risk factors for diarrheal disease incidence in early childhood: a community cohort study from GuineaBissau. Am J Epidemiol 1997; 146:273-82.

12. Mirza NM, Caulfield LE, Black RE, Macharia WM. Risk factors for diarrheal duration. Am J Epidemiol 1997; 146:776-85.

13. Guerrant R, McAullife J. Special problems in developing countries. In: Gorbach SL, ed. Infectious diarrhea. Boston: Blackwell, 1978:287-307.

14. Gomes TAT, Rassi V, MacDonald DL, et al. Enteropathogens associated with acute diarrheal disease in urban infants in Sao Paulo, Brazil. J Infect Dis 1991; 164:331-7.

15. Janda J, Duffey P. Mesophikic aeromonas in human disease: current taxonomy, laboratory identification, and infectious disease spectrum. Rev Infect Dis 1988; 10:980-95.

16. Gomes TA, Vieira MA, Abe CM, Rodrigues D, Griffin PM, Ramos SR. Adherence and adherence-related DNA sequences in Escherichia coli isolates from children with and without diarrhea in Sao Paulo City, Brazil. J Clin Microbiol 1998;36:3609-13.

17. Kaper J. Defining EPEC: proceedings of the international symposium on enteropathogenic Escherichia coli (EPEC). Rev Microbiol 1996; 27: $130-3$.

18. Bruzzi P, Green SB, Byar DP, Brinton LA, Schairer A. Estimating the population attributable risk for multiple risk factors using case-control data. Am J Epidemiol 1985; 122:904-14.

19. Khan MU. Interruption of shigellosis by hand washing. Trans $R$ Soc Trop Med Hyg 1982; 76:164-8.

20. Guerrant R, Kirchoff L. Prospective study of diarrheal illnesses in northeastern Brazil: patterns of disease, nutritional impact, etiologies, and risk factors. J Infect Dis 1983; 148:986-97.

21. Esrey S. Water, waste, and well-being: a multicountry study. Am J Epidemiol 1996; 143:608-23.

22. Dargent-Molina P, James SA, Strogatz DS, Savitz DA. Association between maternal education and infant diarrhea in different households and community environments of Cebu, Philipines. Soc Sci Med 1994; 38:343-50.

23. Monteiro C. Estudo de condicoes de saude das criancas do municipio de Sao Paulo, SP (Brasil), 1984-5. III Aleitamento materno. Rev Saude Publica 1987; 21:13-22.

24. Bartlett AV, Moore M, Gary GW, Starko KM, Erben JJ, Meredith BA. Diarrheal illness among infants and toddlers in day care centers. II. 
Comparison with day care homes and households. J Pediatr 1985; 107:503-9.

25. Louhiala PJ, Jaakkola N, Ruotsalainen R, Jaakkola JJ. Day-care centers and diarrhea: a public health perspective. J Pediatr 1997; 131:476-9.

26. Abu-Elyazeed R, Wierzba TF, Mourad AS, et al. Epidemiology of en- terotoxigenic Escherichia coli diarrhea in a pediatric cohort in a periurban area of lower Egypt. J Infect Dis 1999; 179:382-9.

27. Brown KH, Black RE, de Romana GL, de Kanashiro HC. Infant-feeding practices and their relationship with diarrheal and other diseases in Huascar (Lima), Peru. Pediatrics 1989; 83:31-40. 